Laboratory of Economics and Management Sant'Anna School of Advanced Studies

Piazza Martiri della Libertà, 33 - 56127 PISA (Italy)

Tel. +39-050-883-343 Fax +39-050-883-344

Email: lem@sssup.it Web Page: http://www.sssup.it/ LEM/

\title{
LEM
}

Working Paper Series

\section{Physical and Social Technologies, and Their Evolution}

Richard Nelson *

"Columbia University 
Physical and Social Technologies, and Their Evolution

\author{
Richard R. Nelson \\ Columbia University
}

\title{
Introduction
}

From the beginnings of my career, my principal research interests have been to understand the processes of long-run economic development that have, over the last two-and-ahalf centuries, remarkably lifted the living standards of a significant fraction of the world's population, and which also have left a large fraction behind. From the days when Adam Smith first wrestled with this question, economists have understood that the principal driving force has been the development and utilization of more powerful ways of doing things, sometimes involving new products and services, sometimes more productive ways of producing them, and sometimes both. Adam Smith also was keenly aware that the development and utilization of new "physical technologies" in the above sense often interacted strongly with changing modes of division of labor, and new ways or organizing and governing work, what I have called "social technologies." Recall his famous discussion at the start of The Wealth of Nations in which the development of machinery for pinmaking is linked to the increasing division of labor, both of which in turn are connected to the growing extent of the market.

A good fraction of my work in recent has been dedicated to bringing social technologies into the framework of evolutionary economics that Sidney Winter and I (1982) and many colleagues, have been developing, and to begin to explore the similarities and differences in the ways that physical technologies and social technologies evolve. This essay is largely concerned with this topic. However, before I get into that subject matter, given the orientation of this 
conference it is incumbent on me to relate that discussion to "institutions."

Writings about institutions in economics, and social science more generally, implicitly or explicitly contain a wide variety of particular definitions of what is meant by that term. However, it is apparent that Veblen's "general habits of action and thought" (1898), Commons' "working rules" (1924), North's "rules of the game" (1990) Schotter's "how the game is played" (1981), Williamson's “governing structures" ((1985), and other conceptions of institutions put forth by distinguished economists and social scientists, all have a family resemblance. Specifically, virtually all scholars writing about institutions have aimed to call attention to standardized modes of transacting, and interacting more generally, employed by human and organizational actors to get things done in context where effective performance requires coordinated action. In several places Geoffrey Hodgson (1988, 1998, 2001, 2002) has discussed the history of instutional economics, old and new, in great detail. Under most conceptions of the term, institutions are generally employed relatively standardized social technologies (the way the game is played), or the forces that strongly mold and support that action pattern (the rules of the game).

In our initial foray into this area, Bhaven Sampat and I (2001) opted for the "standard ways of doing things" view on institutions, as contrasted with the factors that mold these, while at the same time pointing out that there is no clean line between these two views. Thus if one considers "physical technologies", as differentiated from social technologies, one often can observe that a particular technology is inextricably connected with particular machinery and other specialized inputs that are employed. This often is reflected in nomenclature, as in the "open hearth method" of making steel. Similarly, the M form of business organization is inextricably connected with a particular kind of division of labor and responsibility among different layers of management. Thus if one refers to the $M$ form as a social technology, one is denoting both a way of making decisions and governing the firm, and an organizational structure which supports this way. 
From this point of view, "institutions" are an important subclass of social technologies more generally - those that are in general and expected use across an area of application, as contrasted with those that vary significantly depending on the particular individuals and organizations involved. However, the lines here clearly are blurry. Many writers talk about, say, Harvard, or IBM, as particular institutions, clearly having in mind "institutionalized" patterns of doing things that are special to those organizations. Also, I think that many writers on institutions would argue that a central attribute is not simply the presence of relatively durable standard patterns of behavior, but a system of formal or informal norms and beliefs that these are the "right" ways to do things. I would agree that institutions almost always have such normative support, but that the matter here may be one of degree not kind.

In any case, the argument and the evidence I present for it here is basically about the differences in evolutionary processes working on physical technologies and social technologies generally, although the social technologies I will use as examples are in widespread use, and are almost expected in the context, and thus they might be regarded as "institutions." My argument will be that society's ability to develop effective "social technologies" is more limited and more prone to frustration that its ability to advance physical technologies. My emphasis will be on the reasons, because the fact of the matter I think is widely agreed upon, although there certainly are some of my colleagues who would object. My orientation, obviously, will be on differences in the nature (on average) of the evolutionary processes at work on physical and social technologies, respectively.

But before I get into the details, I need to lay some groundwork. First, I want to highlight a fact that should be obvious, but sometimes is forgotten. An evolutionary explanation for why one observes the ways of doing things--the physical and social technologies--that are prominent at any time presumes that these ways of doing things are replicable to a certain degree.

Organizations that are employing them must be able to retain them in close to present form, if they choose. If these firms are profitable and seek to expand, they must be able to reproduce in their new units the ways of doing things that have made them profitable. Other organizations not 
using those practices must be able to imitate them reasonably reliably if they choose to, The last of these conditions is not necessary in principle for an evolutionary argument to go through, but in fact imitation of technologies that come widely to be regarded as profitable plays a major role in most of the empirical studies of the evolution of technology that I know about. In any case, if the first two conditions do not hold, an evolutionary process cannot effectively select a particular technology, because what is selected at any time can transmute into something else. The requirement for "selective retention" cannot be met.

Biologists have theorized that an evolutionary process needs to operate on reliable "replicators". This is as true for cultural evolutionary processes as for biological evolution.

Second, systematic selection requires that there be reasonably strong connections between the use of a particular set of practices and organizational performance, and that there be reasonably reliable evidence of the efficacy of different ways of doing things. Again, the latter is not necessary in principle, but in fact judgments and conscious choices almost always are a major part of the story of the evolution of technologies, in many cases playing a more important role than simply relative growth of organizations who are using profitable technologies. But either through survival and expansion of the organizations possessing them, or through conscious choices, a way of doing something must be salient to organizational performance to be subject to systematic selection.

In evolutionary biology, to be selected for or against systematically, a trait must have a strong influence on inclusive fitness. An analogous requirement holds in the kind of evolutionary analysis being employed here.

The argument I will develop, of course, is that both of these conditions usually are more favorable to rapid development of physical technologies than of social technologies, for both direct and indirect reasons. I shall develop that argument as follows:

In Section II I consider what is known about the ways that physical technologies evolve, a subject on which there has been much more empirical research than on social technologies. This will lead in Section III to my argument that, as a rule, social technologies are more difficult 
to improve through an evolutionary process than physical technologies. I will support my argument by several examples. In the concluding section I reflect upon some of the implications.

II. Technological Advance As An Evolutionary Process: What Makes Progress Easy

\section{Or Difficult}

Over the past half-century a large interdisciplinary body of scholarship has developed concerned with understanding the processes through which "physical" technologies advance over time. In contrast, the body of scholarship that has looked in detail at the development of "social" technologies - forms of business organization, management practices, market mechanisms and structures, public policies, legal and regulatory structures, etc. - has been limited and scattered. I begin my discussion, therefore, by presenting key aspects, for the purposes of the current discussion, of what is known about the development of physical technologies. I then will consider the factors that would seem to support rapid sustained progress, and those that would make progress difficult. This analysis will set the stage for my comparison of the ways physical technologies and social technologies evolve.

First of all, scholars of technological advance, from a wide variety of disciplines, have converged on the proposition that technological advance needs to be understood as proceeding through an evolutionary process (see eg. Constant, 1977, Mokyr, 1990, Nelson and Winter, 1982, Petroski, 1992, Vincenti, 1990, Ziman, 2000). The process is evolutionary in the sense that at any time there generally are a wide variety of efforts going on to advance the technology, which to some extent are in competition with each other, as well as with prevailing practice. The winners and losers in this competition are determined largely through an ex-post selection process. And, while many of the scholars writing in this vein do not discuss the matter explicitly, it is implicit in this account that what is selected does not transmute into something significantly different, except by intention.

However, the proposition that technology evolves in the above sense in no way denies, or plays down, the role of human purpose in the process, or the often extremely powerful body of understanding and technique used to guide the efforts of those who seek to advance technology. 
Thus efforts at invention and innovation are by no means totally blind, or strictly random, as often is assumed to be the case regarding biological "mutation." Thus Walter Vincenti (1990) has described the kinds of complex knowledge and technique that modern aeronautical engineers possess, and discusses in detail how these focus and give power to their efforts at design. This body of knowledge and technique both enables engineers to focus their efforts on designs that are seen as having considerable promise, and permits a variety of tests to be made in the course of development that confirm earlier expectations or indicate changes that need to be made.

However, Vincenti, along with other scholars who propose that technological advance is an evolutionary process, argues that efforts at inventing and technological problem-solving almost always reach beyond the range of options that are perfectly understood, and in that sense are somewhat "blind." To a considerable extent, what works and what does not, and what works better than what, therefore must be learned through actual experience and actual competition.

A significant part of the selection process for physical technologies, and ways of doing things more generally, often involves the expansion and decline of firms that work with different variants. However, I proposed above that there are strong elements of conscious selection operating as well. Most of the empirical literature concerned with the diffusion of new technologies presumes that conscious selection is the driving force. Thus in one of the cases we will consider shortly, it is clear that hybrid corn spread among farmers and replaced older seed varieties because farmers came to believe, correctly, that this decision was profitable. During the 1950s, polio vaccines came into widespread use because they were believed by the medical community, on the basis of good evidence, to be highly effective.

Most scholars of technological advance also are united by their insistence that the process needs to be understood as "cultural" in the sense, first, that much of the background knowledge needed for inventing is widely held, and, second, anyone attempting to advance a technology almost always is standing on "the shoulders of giants," or more accurately, drawing on a large body of already achieved technique and understanding that has been developed by predecessors. The selection process also is strongly cultural, with potential adopters of new technology often 
relying heavily on the experience of others who adopted earlier to assess whether an innovation is worthwhile. Indeed this is the key driving mechanism in many models of diffusion.

As the above discussion suggests, technology needs to be understood as comprising both a body of practice, and a body of understanding. Professionals in the field possess not only a considerable amount of "knowhow," but also a body of more analytic knowledge that explains or rationalizes why practices work as they do, illuminates current limitations of the technology, and suggests promising roads down which improvements may be achieved.

In the process of technological advance, both practice and understanding evolve, or I would propose more specifically that technique and understanding coevolve. The development of a particular new product or process generally brings with it a wider body of new understanding that includes, but transcends, the particulars of the new technique. New understandings earned through this route, or through efforts more directly aimed to advance understanding, in turn provide clues and opportunities for the further advance of technique.

But there is much more to the story about how understanding advances than simply learning by doing and using. In the contemporary world, most important technologies are associated with specific institutional fields of engineering or applied science. The body of understanding is to some extent codified in these fields, and serves as the basis for the training of new technologists and applied scientists. And these also are fields of research. It is interesting and important that the fields of technology that, by a variety of different measures, have advanced most rapidly all have associated with them strong fields of engineering or applied science. (See e.g. Klevorick et al, 1995, Nelson and Wolff, 1997). These applied sciences allow, indeed in some cases require, a considerable amount of the work to advance a technology to go on offline, in research and development. This is so for fields as diverse as the development of new seeds, fertilizers, and insecticides in agriculture, the development of new pharmaceuticals in medicine, the design of new semiconductors, or telecommunication systems, or new aircraft.

However, as I argued above, offline $\mathrm{R}$ and $\mathrm{D}$, even when based on powerful underlying science, cannot obviate the need for testing in actual practice. And more generally, technological 
advance cannot be forecasted or planned closely enough to eliminate, or significantly diminish, the value of having competitive approaches. Technological advance remains fundamentally an evolutionary process.

From this perspective, what are the characteristics that can enable the process to be powerful, or on the other hand, tend to limit the possibilities of sustained rapid progress? Consideration of this question will set the stage for my argument that in general it is much more difficult to advance social technologies than physical technologies.

First, as Sidney Winter and I argued argued a long time ago, the competing technologies in question must be sustainable and reproducible. In the language we developed, they must involve a certain amount of "routine". Routines serve as targets for preservation and replication of an activity within an organization that is using them. They also serve as targets for adoption by organizations that presently are not. Technologies where there is very little in the way of "routine" are, from this point of view, difficult to hold in place, and difficult to imitate. At a particular moment of time one may be "selected" because it is effective in its present form, but then may change and lose its effectiveness.

Ability to experiment, and to learn from natural experiments, is an essential part of the process through which technologies get improved, but if a technology cannot be held in place or selected sharply, this makes it almost impossible to experiment with it fruitfully in a controlled way. One can not learn very much from experiments, because there is no clear stable and reproducible practice that can be associated with good performance or poor. Similarly, not much of durable value can be learned from learning by doing or using. This does not make for rapid progress.

Second, the criteria for better performance, or fitness, that the selection environment enforces must be clear and relatively steady, and competing technologies must differ non trivially in efficacy under these standards. If the actors using a particular technology gain no significant advantage over those that do not, and if no clear evidence of advantage is available for those who are contemplating choice, evolutionary forces are going to be weak. And if the 
characteristics that give advantage or are believed to do so vary significantly from period to period, it will be difficult for progress to be cumulative.

Also, as I have noted, technological advance tends to proceed more rapidly when there are a number of minds at work, and many different sources of initiative, and the parties involved are able to learn from and build on each other's successes. That is, competition among organizations or individuals, as well as among technologies, definitely seems to spur progress.

Finally, and here I move beyond my earlier discussion, there obviously are enormous advantages to an innovator in being able to see some distance beyond prevailing practice, and to be able to test with some confidence the likely efficacy of a new design or method without having to build or otherwise put in place a full-scale version and operate it in real time. I argued above that these are exactly the facilitators of invention and innovation given by an underlying strong science. In contrast, it is much more difficult for a technology to advance if learning is largely limited to what can be acquired by doing or using.

I would like to argue that the strength of understanding in the above sense interacts strongly with the other factors influencing the pace of progress. One of the results of the development of a strong science base under a technology often is identification of its key operative elements, and its standardization to some degree. Another useful consequences of strong scientific understanding often is the ability to identify key factors that determine or signal strong or weak performance. Thus a strong science greatly facilitates evaluation. And it often enables ability to test reliably off-line, with investments short of what would be required for full scale implementation, and to gain relatively quick feedback regarding what has promise of working well and what does not. On the other hand, the development of a strong science base may require that the technology itself be amenable to a certain degree of standardization, and to reliable experimentation.

Also, the motivation for the development of a strong applied science would appear to depend on some consistent notions about the characteristics of good performance of that technology. At the same time, the development and maintenance of a community of people all 
familiar with a technology and contributing to its cumulative advance also depends on a certain degree of standardization, and broad consistent agreement regarding just what advancement means. This is facilitated greatly if there is a strong applied science or engineering discipline which codifies and teaches the technology.

III. Semisystematic Differences Between Physical and Social Technologies

While neither group is homogeneous, and in many activities one can see a mix of physical and social technologies that can not easily be seperated (for example mass production methods), I want to propose here that all of the conditions associated with sustained and cumulatively significant evolutionary progress tend to be stronger for physical than for social technologies. Physical technologies (or the physical aspects of technolgies) generally are easier to specify in detail, to maintain, to replicate reliably, and to experiment with in a way that enables learning; they have more of the "routine" about them. Selection criteria tend to be sharper and steadier, and performance is more easily identified and analyzed. In turn these characteristics - specificity regarding key aspects of the technology in question, and relatively clear criteria of merit- facilitate and encourage abstract analysis, and attempts to experiment offline. It is no happenstance that the sciences underlying physical technologies tend to be much stronger than the sciences underlying social technologies. These same characteristics tend to enable comparability across the experiences of different parties, and the development of a broadly shared analytic point of view on the subject matter.

I will try to support this argument by comparing four relatively well studied cases of innovation, two of them relatively clearly "physical" technologies: hybrid corn, and polio vaccines, and two of them clearly "social" technologies: quality circles, and the $M$ form The discussion of these cases is presented in somewhat more detail in my paper with Bhaven Sampat and Alexander Peterhansl. "The Diffusion of Innovations: A Story of Four Models" (2002) which is available upon request. 
Hybrid corn first became available commercially in the 1920s. This achievement was the result of sustained efforts of many agricultural research workers to develop a better corn seed. The search was facilitated by an increasingly strong scientific understanding of plant biology. In the search, "better" was quite well defined, and meant more profitable to grow, all things considered. These other things to be considered included the opportunity cost of the land and labor involved in growing hybrid corn, the fertilizers and insecticides involved, and other particular characteristics involved in the use of hybrid seeds, as contrasted with the alternatives. The seed itself was a clearly defined thing. And the various activities needed of the farmer involved either the seed itself, or things that needed to be done for or to the plants that grew from the seed. These activities could be routinized to a considerable degree, and could be described in terms of routines to be followed..

Because of the high degree of specificity and routinization involved in using hybrid seeds, the results of growing these hybrids in plots in experimentation stations provided credible evidence to farmers as to the results they likely would achieve if they used hybrids, and took care of their crops in the way recommended by the experimentation stations. Similarly, the experience of one farmer in using hybrids provided highly relevant information to his neighbors, who could if they wished buy exactly the same brand of seed, and grow their crops using basically the same techniques.

Hybrids originally were made available in only a small number of regions. The particular characteristics of the seed itself needed to be carefully tailored to the soil type, and climatic characteristics of the region. A seed that worked well in one region would not necessarily work well in another. However, the success of hybrid seeds in the original regions made agricultural scientists, and seed growers, confident that they could develop hybrids that were suitable to other regions. The techniques of developing, and testing, new hybrids were by then well understood, and indeed quite routine. Hybrids quite rapidly were developed for a wide range of regions, and by the 1950 s were used by virtually all farmers who grew corn. 
And the same techniques of creating new and better hybrids in public and private experimentation stations that led to the development of specialized hybrids tailored to the conditions of a wide variety of different regions, also led to the steady improvements of hybrids within each of the regions. The result of all this was a tremendous increase between the 1920s and the 1960s in the total factor productivity of corn production in the United States.

I turn now to a second example: the development of polio vaccines. This development depended upon identification of the virus involved in polio, or in this case three different viruses, which occurred in 1949. The broad set of "physical" techniques for developing a vaccine for infectious illness, once the bacteria or virus causing that illness had been identified, long had been generally known. The underlying sciences and the associated techniques were strong. Thus identification of the viruses set in train several different attempts to develop an effective vaccine for polio.

In the early 1950s Jonas Salk developed what he thought was a promising vaccine using killed virus. Based on that development, an extensive double-blind set of clinical sets was conducted, and the results clearly showed that the incidence of polio for the treated groups was substantially lower than in the controls. Note that the generally accepted criteria here were very sharp: reduced incidence of the disease, and no noticeable negative side effects. Notice also that the technology itself was well defined. It was a particular vaccine.

In the late 1950s Albert Sabin developed a different vaccine for polio, that used live but attenuated virus. Previous experience with vaccines for other diseases indicated that attenuated virus vaccines tended to give longer immunity than killed virus vaccines, but there was a risk that the former itself could cause infection. Tests of the Sabin vaccine showed that it was no more dangerous to use than the Salk vaccine. And in addition to the high probability giving longer immunity, the Sabin also had the advantage of being able to take orally. In most countries use of the Sabin vaccine quickly replaced use of the Salk vaccine.

Again note that the criteria were clear and sharp. The fact that the Sabin vaccine could be taken orally was in effect an extra benefit of a physical technology that clearly rated as 
superior to its predecessor on the generally accepted selected criteria. And note also that the alternatives being evaluated here were sharply different. One used killed virus, and the other attenuated virus. The sharpness of the criteria, the specificity of the technological alternatives, and the strength of the underlying scientific knowledge, clearly greatly facilitated offline research, and experiments on nonhuman animals. However, the ultimate comparison was made in a controlled experiment online. And the specificity of the technologies, and the clearness of the criteria, also made it possible for many professionals to be involved in the developments, in one way or another. Turning now to our first "social technology- quality circles- the history is so incredibly different. Quality circles became fashionable as a "social technology" to be used within business firms during the early and mid1980s, a period of time when Japanese firms were doing extremely well in competition with American firms in certain industries, and American firms and scholars in management were trying to understand the sources of the Japanese prowess, so that American firms could adapt and adopt.

At a very high level of abstraction, the proposition that using quality circles was efficacious could be posed in terms of the long-run profitability of the enterprise. However, the theory about why the use of quality circles would prove profitable for the enterprise involved an amalgam of propositions, some focused directly on the notion that they would help to improve product and process "quality" and through that route improve profitability, and some posed more broadly in terms of the desirability of getting more worker involvement, both objective and subjective, in guiding the management of the enterprise. The core of the quality circle concept generally was agreed to be the regular meeting of small groups of workers who together would try to get clear on how current practices affect product quality, and to identify changes that would enhance product quality. But it was widely recognized that how individual firms went about doing this did, and probably should, differ significantly from firm to firm.

During the early 1980s there was surge of articles, some focused on the Japanese experience, and many oriented toward analysis of American firms which had adopted quality 
circles. These articles recognized that having a quality circle meant different things in different firms. Nonetheless, the orientation was toward trying to evaluate the quantity and quality of the improvements engendered through quality circles. A number of the studies were content with the identification and description of certain specific improvements, that they thought could be ascribed to the work of quality circles. Others aimed to do a statistical analysis. Almost all of the latter studies yielded no statistically significant results. In a way this is not surprising because, on the one hand, the independent variable certainly was very heterogeneous, and on the other hand, there was no sharp agreement on exactly how the effectiveness of quality circles should be measured.

Partly at least because of the absence of real evidence that having a quality circle was efficacious, various studies show a significant decline in the number of articles reporting on or advocating quality circles after the mid-1980s. And it is highly probable that the number of firms who had organized structures that they "called" quality circles diminished as well.

On the other hand, several scholars have proposed that quality circles were part of a general set of developments regarding managerial practice that has moved things in the right direction. Thus Sidney Winter (in Cole and Scott, 2000) has argued that the package of proclivities associated with greater concern on the part of firms with the quality of their products, combined with mechanisms to pay detailed attention to the processes going on in the firm that affected product quality, and involvement in the analysis of workers who were part of those processes, undoubtedly was a good thing. Cole and Scott (2000) basically endorse this position, by asking the following:.

"Is it possible that some of the early publicized failures identified by academic researchers, such as quality circles, actually laid the groundwork for some of the later successes? If so, this would suggest that organizational researchers might well examine management fads in a broader time and space framework"

So there very well may have been some real progress made here in an evolving "social technology." But if so, the process certainly has been very different than that associated with progress based on a physical technology, and while direct comparison is impossible, because no 
one still knows how to measure the effect of better quality management, it is a very safe bet that the cumulative progress achieved under the regime of hybrid corn technology or of polio vaccines has been enormously greater than the cumulative advance achieved under quality management.

As a second example of a new social technology, I want to consider the development and spread of the M form. As Alfred Chandler (1977) tells the story, the M form came into existence in the early part of the twentieth century, as a number of firms who had increased the range of products they produced or the number of markets in which they were active struggled with the management problems of enlarged scale and scope. The standard form of business organization at that time involved a number of functional departments, like finance, marketing, and production, which in turn reported to top management. The enlargement of the variety of things that firms were doing meant that each of these departments now had to deal with a more heterogeneous, as well as a larger, set of things. The idea for the $\mathrm{M}$ form was to divide the company up into divisions, with each division having full responsibility for a small range of products and one or a few markets. Each of the divisions would then have their own functional departments, who now would be able to deal with matters of smaller scale and scope. The function of top management was to monitor the divisions.

It would seem apparent that the adoption of the $M$ form would reduce the complexity and variety of the tasks faced by middle-level management. It also would reorient, and to some extent make more coherent, the task of top management. But there was the question of "the bottom line"; to what extent would the adoption of the M form actually increase firm efficiency, and profitability?

It was and is virtually impossible to confidently assess the real efficiency advantages associated with the adoption of the $\mathrm{M}$ form for two reasons. First, unlike a polio vaccine, or the use of a hybrid corn seed, controlled experimentation was and is impossible in this case. And with so many other things going on in the environment, and often in the firm, there is no real way that the effect of adoption of the $\mathrm{M}$ form in and of itself on profitability can reliably be 
estimated. Second, several studies have shown clearly that the $M$ form was different things in different companies, and even within a given company tended to change over time. For these reasons, adherence to the notion that large diversified firms should manage through the $\mathrm{M}$ form became, and remains, something that is justified to a considerable extent as a matter of faith, and logical argument that is much more abstract and simplified than the actual contexts in which firms operate.

It would seem that something like the $\mathrm{M}$ form remains the standard mode for organizing large and diversified business. Without doubt, individual businesses learned some things through their experiences with their organizational and managerial structures that has enabled them to get out some of the serious bugs. But to my knowledge, there exists no serious research which has argued that the $\mathrm{M}$ form, as a way of organizing large complex businesses, has been significantly refined and improved over the years so that the structures it has today are significantly more efficient than the structures associated with the $M$ form twenty years ago, or fifty.

IV. On the Uneven Improvement of the Ways Things Are Done

From the days of Adam Smith, economists studying economic growth have recognized technological advance as the key driving force. And Smith also recognized the strong interactions between advances in physical technologies, and changes in the way work was organized and governed. Economic progress needs to be understood as involving the evolution of both physical and social technolgies.

Since the times of Thomas Malthus, economists also have recognized that the advance of technology does not proceed at the same pace in all relevant fields. Malthus saw manufacturing technology as continuing to improve rapidly, but agricultural technology as stagnant, with profound long-run consequences for the progress of the human race. He turned out to be far too pessimistic regarding the possibilities for technological advance in agriculture, but the more 
general point about uneven advance across fields, with the fields advancing most slowly in some cases becoming an increasingly heavy drag on progress, does seem to hold true. Some years ago William Baumol (1967) wrote a fascinating article on just this. The growing concerns about our apparent limited ability to improve the effectiveness and productivity of education, for example, indicates this problem is real, and very much with us.

Some technologies may be innately more difficult to improve than others, because it is very difficult to get quick, sharp feedback on what is effective and what isn't, or because there are major reasons why routinization is difficult or undesirable, or both. Thus an important reason why

progress 
seems to be so slow in dealing with breast and prostate cancers is that it takes a long time for there to be solid information whether a new treatment actually is saving lives or not. The same problem of slow and difficult to interpret feedback certainly is part of the reason why it is proving so difficult to improve educational practice. In addition, in education the heterogeneity of the student population, and the varied individual skills of teachers, makes attempts to "routinize" what is done very difficult, and often counterproductive.

I would like to propose that in today's world the technologies that are proving hardest to advance very often have a large element of the social, and a limited role of the physical. The "service" sectors that were the focus of Baumol's analysis fit this mold, and certainly education does. In an earlier paper (Nelson, forthcoming) I compared the difficulties we have in learning to improve educational practice with the successes that often have been achieved in medicine along lines similar to those I used earlier in this essay. And I noted that much of the advance we have achieved in medicine has involved the discovery or development of new physical technologies: vaccines, pharmaceuticals, surgical procedures that involve a raft of physical equipment. The cases of limited progress in breast and prostate cancers, and AIDs, tells us that even in fields where there is a lot of physical technology, progress may still be difficult in places. But it is a good bet that if and when progress is made in these areas, the new treatments will involve new physical technologies

As I also noted earlier, in many cases where significant advance has been achieved in areas where technology had been largely social, this has been the consequence of substitution of physical technologies for aspects of the social. The increasing mechanism of mass production that occurred in the period between 1920 and 1960 is one example. The increasing use over the last decade of electronic communication in large complex organizations is another.

But while physical technologies are much easier to advance than social technologies, and in many cases the advance of what had been social technologies has involved the introduction of new physical technologies, we remain far from a fully automated society, and there is good reason why we can not and do not want to go too far down that road. In particular, there are 
limits to the extent a society ought to want to "automate" its high level decision and governing processes.

Today some of our most difficult problems involve discovering, inventing, and developing the social technologies needed to make new physical technologies effective. Arguably the lion's share of the strains currently on our health care systems are the result of advances in physical medical technologies that societies have not yet learned how to manage and pay for. The continuing turmoil since 1980 in the organization of the industries involved in one way or another with telecommunications displays the problem in another guise. In neither of these areas does the relevant social science point clearly to an appropriate organizational solution, although some of my friends in economics argue as if it did. And the spontaneous "evolutionary" processes that are at work, with many approaches tried, and some at any time succeeding and others failing, are not likely to lead to a satisfactory solution in the near future. Just what a selection environment is selecting on is not clear, and successive waves of fads signal that the criteria are not steady either. If something is found to that appears to work for a while, it may not be clear what are its key elements, and thus it may be difficult to hold in place. Further, the fact that it works today does not necessarily mean it will work tomorrow.

The two cases of "social technologies" I used as examples in this essay are ones where in principle at least there can be and was coexistence of many alternatives at any time, and many independent decision making units. At least in this context, there is a chance of learning by competitive doing and using. However, in many cases the adoption, or abandonment, of a social technology requires collective action, as when certain patterns of action are required or forbidden by law, or where a government agency is a major actor. Thus in the cases above, public policies, and how they change over time, will profoundly influence how our medical care system will evolve, and what will happen regarding the way we organize telecommunications. And this makes the process of evolutionary improvement even more difficult.

I want to conclude by noting that the marriage of evolutionary and institutional economics that is the heart of this essay is, in a sense, a renaissance of an old tradition. Veblen 
(1998) was of course both an institutional and an evolutionary economist, and this combination marked a considerable portion of the old institutional economics tradition in the United States. (See Hodgson, 1999, 2002). It can be argued that a problem with the old institutionalists was that they never worked out the details of their evolutionary economics. I believe that a major problem with the "New Institutional Economics" is that it has thus far failed to take aboard the "New Evolutionary Economics". I believe that modern economic evolutionary theory can add a lot of analytic power to the new institutional economics. And at the same time, if modern economic evolutionary theory is to make progress on its promise to provide a powerful theory of economic growth, it must bring institutions firmly into its orbit. 


\section{References}

Baumol, W., AMacroeconomics of Unbalanced Growth: The Anatomy of the Urban Crisis@, American Economic Review, June, 1967

Chandler, A., Strategy and Structure: Chapters in the History of the Industrial Enterprise, MIT press, Cambridge, 1962

Chandler, A., The Visible Hand:The Managerial Revolution in American Business, Harvard Un. Press, Cambridge, 1977

Cole, R., and Scott, W. R.(eds), The Quality Movement and OrganizationTheory, Sage Publishing, Thousand Oaks, 2000

Commons, J., Institutional Economics, Un. Wisconsin Press, Madison, 1934

Constant, E., The Origens of the Turbojet Revolution, Johns Hopkins Press, Baltimore, 1980

Cyert, R., and March, J., A Behavioral Theory of the Firm, Prentice Hall, New Jersey, 1963

Hodgson, J., Evolution and Institutions: On Evolutionary Economics and the Evolution of Economics, Edward Elgar, Cheltenham, 1999

Hodgson, G., Reconstructing Institutional Economics: Evolution, Agency, and the Structure of American Institutionalism, Manuscript, 2002

Klevorick, A., Levin, R., Nelson, R., and Winter, S., ASources and Significance of Interindustry Differences in Technological Opportunity $\cong$ Research Policy, 1995

Mokyr, J., The Lever of Riches, Oxford Un. Press, Oxford, 1990

Nelson, R., and Winter, S., An Evolutionary Theory of Economic Change, Harvard Un. Press, 1982

Nelson, R., and Sampat, B., Making Sense of Insittutions as a Factorhaping Economic Performance $\cong$, Journal of Economic Behavior and Organization, 2001

Nelson, R., and Wolff, E., AFactors Behind Cross Industry Differences in Technological Progress $\cong$ Structural Change and Economic Dynamics, 1997

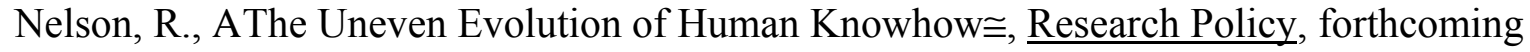

Nelson, R., Peterhansl, A., and Sampat, B., AWhy and How Innovations Get Addopted: A Tale

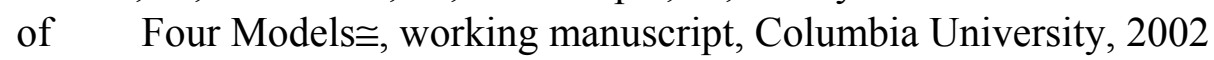


North, D. Institutions, Institutional Change, and Economic P \{erfpormance, Cambridge Un. Press, Cambridge, 1990

Petroski, H., The Evolutiuon of Useful Things, Alfred Knoph, N.Y., 1992

Schotter, A., The Economic Theory of Social Institutions, Cambridge Un. Press, Cambridge, 1981

Schumpeter, J., Capitalism, Socialism, and Democracy, Harper and Row, N. Y., 1942

Smith, A., The Wealth of Nations,Modern Library, N. Y., 1937

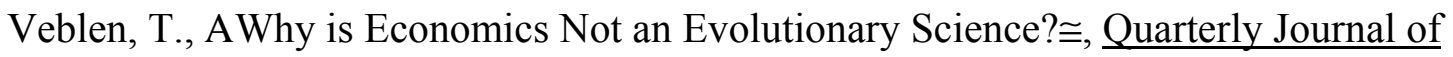
Economics, 1898

Vincenti, W., What Engineers Know and How They Know it, Johns Hopkins, Baltimore, 1990

Williamson, O., The Economic Institutions of Capitalism, Free Press, N.Y., 1985

Williamson, O.,The Mechanisms of Governance, Oxford Un. Press, Oxford, 1995

Winter, S. Organizing for Continuing Improvment؟, in Cole and Scott, 2000

Ziman, J. (Ed.), Technological Innovation as an Evolutionary Process, Cambridge Un.

Press, Cambridge, 2000s 